Ли Сюй-кандидат политических наук, старший преподаватель Института марксизма ВосточноКитайского университета политологии и права (200042, Китай, г. Шанхай, ул. Вань Хан Ду, 1575; lixu1210@mail.ru)

\title{
ИССЛЕДОВАНИЕ ПОЛИТИЧЕСКОЙ ПОЗИЦИИ СТУДЕНТОВ УНИВЕРСИТЕТОВ В ЭПОХУ ИНТЕРНЕТА
} (на основе анкетных опросов в 5 университетах г.Шанхая) ${ }^{1}$

\begin{abstract}
Аннотация. В статье на основании исследования политических взглядов студентов 5 университетов Шанхая, проведенного путем анкетного опроса, проанализированы политические взгляды студентов, которые выросли в эпоху Интернета. Исследование также подтвердило, что Интернет оказывает значительное влияние на политические ориентации студентов.
\end{abstract}

Ключевые слова: Интернет, студент, политические взгляды

$\Pi^{2}$ олитические взгляды человека являются результатом его политической социализации и тесно связаны с его личным опытом, формой и содержанием его образования, а также внешней социальной средой. Наступление эры Интернета создало виртуальное публичное политическое пространство для пользователей сети, где информация, имеющая отношение к политике, передается, обменивается, оказывает влияние на политические взгляды интернетпользователей. Какова же политическая позиция китайских интернет-пользователей в эпоху информационного взрыва в Интернете и одновременно его государственного регулирования?

Как особая группа, студенты университета сыграли важную роль в развитии китайской политической демократии. Тем не менее исследования политических ориентаций этой группы встречаются редко. В 1996 г. Эндрю Дж. Натан и Ши Тяньцзянь включили уровень образования в аналитические переменные исследования идеологии китайцев в эпоху Дэн Сяопина (начало 1990-х гг.). Автор этого исследования считает, что уровень образования является наиболее важной переменной, влияющей на политическую позицию студентов университетов [Nathan, Tianjian Shi 1996].

В рамках данного исследования был проведен анкетный опрос студентов 5 университетов Шанхая с целью эмпирического анализа политической позиции студентов в эпоху Интернета. Данное исследование в основном отвечает на 3 вопроса: во-первых, политическое восприятие студентов университетов, их политическая позиция и использование средств массовой информации; во-вторых, различия и взаимосвязь между разными аспектами политических взглядов студентов; в-третьих, степень влияния общения в Интернете на политическую позицию студентов.

Анкетный опрос был проведен анонимно, и в качестве респондентов были отобраны 500 студентов. Пять университетов, включенных в этот опрос, являются образцово-показательными (4 университета непосредственно подчиняются Министерству образования, один - муниципалитету Шанхая, включают

\footnotetext{
1 Проект фонда. Эта статья была профинансирована в рамках исследовательской программы Восточно-Китайского университета (№ А-1401-19-002-25).
} 
университеты общего профиля, специализирующиеся на науке и технике, инженерии, финансах и иностранных языках), и в целом могут полностью отражать состав студентов высших учебных заведений страны.

В опросе участвовали студенты, обучающиеся по гуманитарному и социальному профилю $(80,3 \%)$ и обучающиеся по естественнонаучным и техническим дисциплинам (19,7\%). С точки зрения политического статуса наивысшую долю составляют члены организаций $(61,8 \%)$, вслед за ними идут вступающие в партию активисты $(18,5 \%)$, члены партии $(14,5 \%)$, затем остальные $(5,2 \%)$. В их числе преобладают городские жители $(73,8 \%)$, доля деревенских жителей составляет $10,8 \%$. С точки зрения занятости родителей максимальную долю студентов составляют те, у которых родители - из числа руководящего персонала партийных и административных органов и бюджетных учреждений, далее из рабочих и служащих предприятий; занимаются земледелием, лесоводством, рыбным хозяйством и животноводством не более $10 \%$ родителей опрошенных студентов.

Исследование политической грамотности и политического восприятия респондентов показало, что при овладении некоторыми базовыми политическими знаниями уровень правильности ответов студентов, изучающих гуманитарные и общественные науки, гораздо выше, чем у студентов, изучающих естественные и инженерные науки. Исследование показало различия в степени овладения некоторыми базовыми политическими знаниями среди студентов университетов с различным политическим статусом. Вопреки ожиданиям, политическая грамотность и безошибочность мнения среди членов партии даже ниже, чем у прочих категорий учащихся, что вызывает некоторые проблемы. Так, отвечая на вопрос: «Какой орган выдвинул Си Цзиньпина для избрания председателем государства», - только 58,6\% членов партии ответили правильно, что является самым низким уровнем среди всех политических кате-

Таблица 1

Национализм в политических взглядах, \%

\begin{tabular}{|c|c|c|c|c|c|}
\hline Мнение & 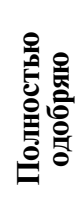 & 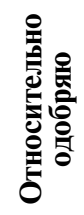 & : & 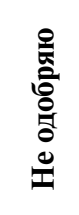 & 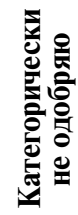 \\
\hline Китайская нация - лучшая нация в мире & 29,7 & 22,4 & 33,8 & 10,8 & 3,3 \\
\hline $\begin{array}{l}\text { Национальные праздники, такие как военный } \\
\text { парад, посвященный Национальному дню, } \\
\text { являются важным образовательным аспектом для } \\
\text { стимулирования патриотизма }\end{array}$ & 57,7 & 26,1 & 13,9 & 2,3 & 0 \\
\hline $\begin{array}{l}\text { Западные страны, возглавляемые Соединенными } \\
\text { Штатами, не хотят мириться с подъемом Китая }\end{array}$ & 11,8 & 37,3 & 37,6 & 11,6 & 1,7 \\
\hline $\begin{array}{l}\text { Бойкот японских товаров есть выражение } \\
\text { патриотизма }\end{array}$ & 7,3 & 13,5 & 28,8 & 31,5 & 18,9 \\
\hline $\begin{array}{l}\text { При определенных условиях допускается } \\
\text { максимально быстро применить военную силу для } \\
\text { разрешения конфликта на островах Дяоюйдао и в } \\
\text { тайваньском вопросе }\end{array}$ & 6,2 & 12,4 & 30,5 & 36,9 & 13,9 \\
\hline
\end{tabular}


Либерализм в политических взглядах, \%

\begin{tabular}{|c|c|c|c|c|c|}
\hline Мнение & 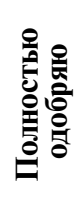 & 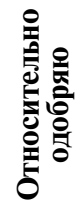 & 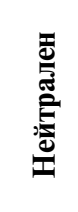 & 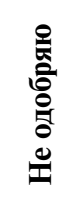 & 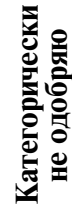 \\
\hline $\begin{array}{l}\text { Такие общечеловеческие ценности, как свобода, } \\
\text { демократия, права человека, не существуют }\end{array}$ & 4,4 & 13,1 & 26,6 & 37,3 & 18,7 \\
\hline $\begin{array}{l}\text { Правительство должно при любых } \\
\text { обстоятельствах гарантировать гражданам права } \\
\text { и свободы: свободу слова, право создавать } \\
\text { общества, право выходить на демонстрации }\end{array}$ & 24,3 & 34,6 & 28,6 & 11,6 & 0,8 \\
\hline $\begin{array}{l}\text { Необходимо принять максимально жесткие } \\
\text { меры, чтобы обуздать коррупцию в чрезвычайно } \\
\text { короткий период }\end{array}$ & 28,2 & 44,0 & 21,6 & 5,2 & 1,0 \\
\hline $\begin{array}{l}\text { Национальные и коллективные интересы выше } \\
\text { личных интересов }\end{array}$ & 14,9 & 31,7 & 39,0 & 12,2 & 2,1 \\
\hline
\end{tabular}

горий. По другим вопросам члены партии также не проявили отчетливое превосходство.

Анкета «Политическая позиция респондентов» отражала политическую позицию студентов университетов по 7 позициям: национализм, либерализм, рыночная экономика, политическая демократия, честность и справедливость, участие в политической жизни и политическое образование.

В табл. 1 обобщается отношение студентов к проблемам национализма. Можно увидеть, что большинство студентов университетов имеют сильное чувство национальной гордости, при этом тенденции к ультранационализму не проявляются. По утверждениям: «Китайская нация - лучшая нация в мире» и «Национальные праздники, такие как военный парад, посвященный Национальному дню, являются важным образовательным аспектом для стимулирования патриотизма» соотношение одобряющих составляет 52,1 и 83,8\% соответственно, что намного выше, чем доля противников. В отношении тезиса о том, что «западные страны, возглавляемые Соединенными Штатами, не хотят мириться с подъемом Китая», соотношение одобряющих это мнение студентов и придерживающихся противоположного мнения приблизительно одинаковы. По утверждениям: «Бойкот японских товаров есть выражение патриотизма» и «При определенных условиях допускается максимально быстро применить военную силу для разрешения конфликта на островах Дяоюйдао и в тайваньском вопросе» подавляющее большинство студентов не согласны с данным мнением, а доля одобрений, выраженных в разной степени, составляла не более 20\%. В целом, можно сказать, что современные студенты университетов являются рациональными патриотами.

Анкета оценивает либеральные тенденции студентов на основании информации об отношении студентов к свободе, демократии, правам человека, другим нравственным ценностям, личным и коллективным отношениям, государст- 
Отношение к рыночной экономике в политической позиции, \%

\begin{tabular}{|c|c|c|c|c|c|}
\hline Мнение & 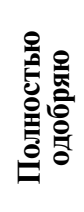 & 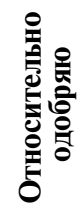 & 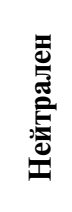 & 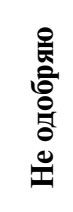 & 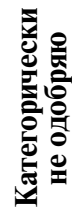 \\
\hline $\begin{array}{l}\text { Земля должна принадлежать государству, а не } \\
\text { быть предметом частной собственности }\end{array}$ & 10,0 & 16,6 & 54,1 & 16,2 & 3,1 \\
\hline $\begin{array}{l}\text { Защита развития национальной промышленности } \\
\text { с помощью таможенных или импортных мер }\end{array}$ & 7,5 & 27,4 & 39,8 & 20,5 & 4,8 \\
\hline $\begin{array}{l}\text { Государственные предприятия должны } \\
\text { всесторонне контролировать сферы экономики, } \\
\text { имеющие отношение к национальной } \\
\text { безопасности, планам развития экономики } \\
\text { государства и улучшения благосостояния народа }\end{array}$ & 7,5 & 20,5 & 39,4 & 26,6 & 6,0 \\
\hline $\begin{array}{l}\text { Правительство должно расширять экономические } \\
\text { реформы, а вмешательство в рыночную } \\
\text { экономику должно быть как можно меньшим }\end{array}$ & 14,3 & 22,4 & 40,9 & 19,9 & 2,5 \\
\hline $\begin{array}{l}\text { Разрыв между богатыми и бедными и классовое } \\
\text { расслоение является результатом рыночной } \\
\text { экономики }\end{array}$ & 7,1 & 21,0 & 39,2 & 28,6 & 4,1 \\
\hline
\end{tabular}

венной власти. Как показано в табл. 2, студенты университетов демонстрируют некоторую неоднозначность мнений. С одной стороны, более $56 \%$ студентов университетов выступают против вывода о том, что «такие общечеловеческие ценности, как свобода, демократия, права человека, не существуют». Наряду с этим более $58 \%$ студентов считают, что «правительство должно при любых обстоятельствах гарантировать гражданам права и свободы: свободу слова, право создавать общества, право выходить на демонстрации». Это показывает, что современные студенты университетов имеют сравнительно высокую степень признания ценности прав человека и системы основных нравственных ценностей. С другой стороны, почти половина студентов согласились с тем, что «национальные и коллективные интересы выше личных интересов», и почти $3 / 4$ студентов признают, что «необходимо принять максимально жесткие меры, чтобы обуздать коррупцию в чрезвычайно короткий период». Это, по мнению исследователей, результат не только прагматической позиции студентов по таким аспектам, как свобода, права человека, нравственные ценности, но и многообразия внутреннего понимания студентами свободы, демократии и прав человека.

Понимание рыночной экономики обычно тесно связано с либеральной позицией. Из данных табл. 3 следует, что позиция студентов в отношении рыночной экономики не демонстрирует ни явную поддержку, ни оппозицию. Путем анализа можно обнаружить, что, поскольку студенты университетов имели противоречивую позицию в отношении либерализма, существуют противоречия и в их понимании рыночной экономики. С одной стороны, студенты согласны с тем, что «земля должна принадлежать государству, а не быть предметом частной собственности», «правительство должно расширять экономические реформы, 
Политическая демократия в политической позиции, \%

\begin{tabular}{|c|c|c|c|c|c|}
\hline Мнение & 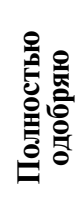 & 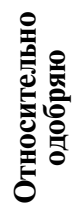 & 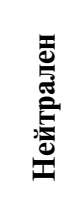 & 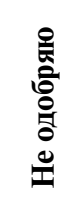 & 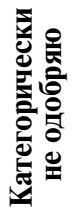 \\
\hline $\begin{array}{l}\text { Не следует публично и широкомасштабно } \\
\text { обсуждать проступки политического деятеля Мао } \\
\text { Цзэдуна }\end{array}$ & 7,7 & 21,0 & 42,9 & 21,2 & 7,3 \\
\hline $\begin{array}{l}\text { Конфуцианство и традиционная культура - пути } \\
\text { решения проблем Китая }\end{array}$ & 3,5 & 16,8 & 42,7 & 28,6 & 8,3 \\
\hline $\begin{array}{l}\text { Разделение власти не соответствует требованиям } \\
\text { Китая }\end{array}$ & 13,9 & 36,9 & 34,0 & 12,2 & 2,9 \\
\hline $\begin{array}{l}\text { Политическое развитие Китая должно } \\
\text { гарантировать гражданские права, ограничивать } \\
\text { государственную власть и обеспечивать } \\
\text { верховенство закона }\end{array}$ & 43,4 & 36,3 & 18,3 & 1,5 & 0,6 \\
\hline $\begin{array}{l}\text { Китай должен идти по социалистическому пути } \\
\text { под руководством марксизма-ленинизма }\end{array}$ & 31,7 & 33,8 & 30,1 & 2,7 & 1,7 \\
\hline $\begin{array}{l}\text { Электоральная демократия ложна, не отвечает } \\
\text { требованиям Китая }\end{array}$ & 8,5 & 11,2 & 30,1 & 38,4 & 11,8 \\
\hline $\begin{array}{l}\text { Народная демократия по сравнению с западной } \\
\text { демократией имеет больше преимуществ }\end{array}$ & 14,9 & 20,3 & 47,5 & 13,7 & 3,5 \\
\hline
\end{tabular}

а вмешательство в рыночную экономику должно быть как можно меньшим», доля согласных с утверждением, что «разрыв между богатыми и бедными и классовое расслоение являются результатом рыночной экономики», выше, чем придерживающихся противоположного мнения. С другой стороны, более высокая доля студентов считают, что «развитие национальной промышленности должно быть защищено с помощью таможенных пошлин или импортных мер» и что «государственные предприятия должны всесторонне контролировать сферы экономики, имеющие отношение к национальной безопасности, планам развития экономики государства и улучшения благосостояния народа».

Результаты исследования позиций студентов в отношении политической демократии демонстрируют данные табл. 4. Современные студенты нисколько не игнорируют политическое устройство западных стран, но в то же время полны уверенности в преимуществах существующей политической системы Китая. В ответах на 7 вопросов, затрагивающих эту тему, 79,7\% студентов университетов выражают мнение, что «Политическое развитие Китая должно гарантировать гражданские права и свободы, ограничивать государственную власть и обеспечивать верховенство закона», 65,5\% студентов согласны с тем, что «Китай должен идти по социалистическому пути под руководством марксизма-ленинизма». В утверждениях, что «разделение власти ${ }^{1}$ не подходит Китаю» и «народная демократия по срав-

\footnotetext{
1 Прим. переводчика: на законодательную, исполнительную и судебную.
} 
Политическая позиция по участию в политической жизни, \%

\begin{tabular}{|c|c|c|c|c|c|}
\hline Мнение & 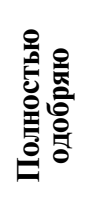 & 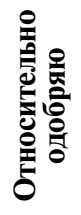 & 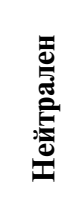 & 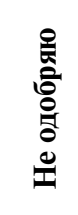 & 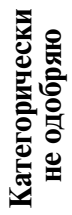 \\
\hline $\begin{array}{l}\text { Независимо от того, какая это партия или лидер, } \\
\text { необходимо ограничивать их власть }\end{array}$ & 39,6 & 39,6 & 17,2 & 2,9 & 0,6 \\
\hline $\begin{array}{l}\text { Решения правительства и лидеров, как правило, } \\
\text { безошибочны }\end{array}$ & 7,5 & 10,4 & 31,5 & 37,8 & 12,9 \\
\hline $\begin{array}{l}\text { До тех пор, пока правящая партия и ее лидеры } \\
\text { бескорыстно служат обществу, простому народу } \\
\text { нет нужды слишком много участвовать в } \\
\text { принятии решений }\end{array}$ & 8,1 & 7,9 & 17,8 & 43,4 & 22,8 \\
\hline $\begin{array}{l}\text { Мнения экспертов и интеллектуалов следует } \\
\text { учитывать в большей степени, чем мнение } \\
\text { простого народа }\end{array}$ & 9,3 & 18,5 & 28,2 & 32,2 & 11,8 \\
\hline $\begin{array}{l}\text { Чтобы уменьшить ненужные неприятности, } \\
\text { правительство старается не разглашать } \\
\text { подробности конкретного процесса принятия } \\
\text { решений }\end{array}$ & 7,5 & 9,5 & 19,9 & 38,4 & 24,7 \\
\hline
\end{tabular}

нению с западной демократией имеет больше преимуществ» хотя почти 1/3 студентов занимают нейтральную позицию, доля одобряющих по-прежнему превышает долю противников. Тем не менее по утверждениям: «Электоральная демократия ложна, не отвечает требованиям Китая» и «Конфуцианство и традиционная культура являются способом решения проблем Китая» доля противников выше (не считая нейтральных). Интересно отметить, что по утверждению: «Не следует публично и широкомасштабно обсуждать проступки выдающегося политического деятеля Мао Цзэдуна» позиция опрошенных студентов университетов показала нормальный характер распределения. В целом студенты университетов имеют сравнительно высокую уверенность в правильности собственного демократического пути Китая.

Исследование показало, что в социальных вопросах студенты университетов в целом обладают сильным чувством честности и справедливости. 76,6\% студентов согласны с тем, что «дети трудящихся-мигрантов должны иметь равные права на образование», а 70,1\% студентов университетов согласны с тем, что «правительство должно обеспечить минимальные социальные гарантии людям с низким уровнем дохода». Более половины студентов согласны с тем, что «повышение налогообложения богатых уменьшает неравенство».

Как показал опрос (см. табл. 5), современные студенты обладают довольно сильной степенью осознания участия в политической жизни и сохраняют определенный скептицизм в отношении роли правительства, его лидеров, экспертов, интеллигенции и других представителей элиты в политическом процессе, требуя, чтобы политический процесс был прозрачным и власть обращала внимание на мнение простых людей.

Опрос показал, что Интернет является основным каналом информации для 
Таблица 6

\section{Взаимосвязь между различными политическими позициями}

\begin{tabular}{|c|c|c|c|c|c|c|c|c|}
\hline & & 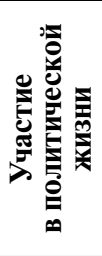 & 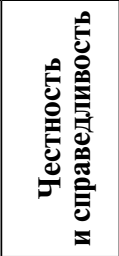 & 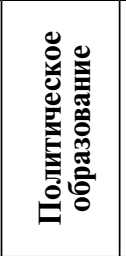 & 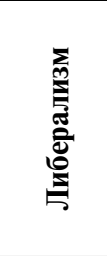 & 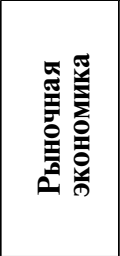 & 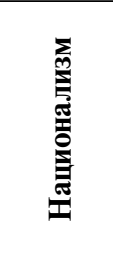 & 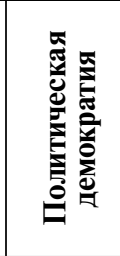 \\
\hline \multirow{2}{*}{ 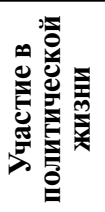 } & Коррелятивность & 1 & $-.120 * *$ & $-.158 * *$ & $.360 * *$ & $.277^{* *}$ & -.079 & $.522 * *$ \\
\hline & $\begin{array}{l}\text { Достоверность } \\
\text { (Двухсторонняя) }\end{array}$ & - & .008 & .000 & .000 & .000 & .085 & .000 \\
\hline \multirow{2}{*}{ 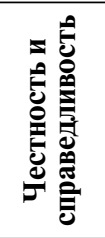 } & Коррелятивность & - & 1 & $.099 *$ & -.055 & $-.112^{*}$ & .072 & $-.252^{* *}$ \\
\hline & $\begin{array}{l}\text { Достоверность } \\
\text { (Двухсторонняя) }\end{array}$ & - & - & .030 & .228 & .014 & .117 & .000 \\
\hline \multirow{2}{*}{ 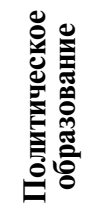 } & Коррелятивность & - & - & 1 & -.051 & $-.277^{* *}$ & $.356^{* *}$ & $-.392 * *$ \\
\hline & $\begin{array}{l}\text { Достоверность } \\
\text { (двухсторонняя) }\end{array}$ & - & - & - & .265 & .000 & .000 & .000 \\
\hline \multirow{2}{*}{ 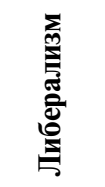 } & Коррелятивность & - & - & - & 1 & $.354 * *$ & $-.109^{*}$ & $.293 * *$ \\
\hline & $\begin{array}{l}\text { Достоверность } \\
\text { (Двухсторонняя) }\end{array}$ & - & - & - & - & .000 & .017 & .000 \\
\hline \multirow{2}{*}{ 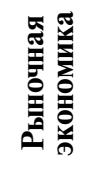 } & Коррелятивность & - & - & - & - & 1 & $-.185^{* *}$ & $.397 * *$ \\
\hline & $\begin{array}{l}\text { Достоверность } \\
\text { (Двухсторонняя) }\end{array}$ & - & - & - & - & - & .000 & .000 \\
\hline \multirow{2}{*}{ 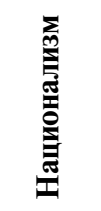 } & Коррелятивность & - & - & - & - & - & 1 & $-.381^{* *}$ \\
\hline & $\begin{array}{l}\text { Достоверность } \\
\text { (двухсторонняя) }\end{array}$ & - & - & - & - & - & - & .000 \\
\hline \multirow{2}{*}{ 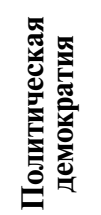 } & Коррелятивность & - & - & - & - & - & - & 1 \\
\hline & $\begin{array}{l}\text { Достоверность } \\
\text { (Двухсторонняя) }\end{array}$ & - & - & - & - & - & - & - \\
\hline
\end{tabular}

Примечание: ** - показатель $\mathrm{p}<0,01,{ }^{*}-$ показатель $\mathrm{p}<0,05$. 
студентов, за ним следуют телевидение, газеты, журналы и радио. Студенты склонны использовать Интернет, когда нуждаются в активном понимании информации, однако в отношении авторитетности информации они больше доверяют телевидению как традиционному средству массовой информации. Несмотря на то что студенты пользуются Интернетом очень часто, число контактов и обсуждение политических вопросов в сети довольно ограниченно. $21,8 \%$ практически не затрагивают политические проблемы в социальных сетях, а 24,8\% опрошенных никогда не участвовали в политических дискуссиях в социальных сетях. С 2009 г. все университеты Шанхая начали продвигать использование Yiban под руководством Департамента управления образованием, пытаясь сделать его сетевым интерактивным сообществом, объединяющим образование, преподавание, службу жизнеобеспечения, культурные развлечения, способным заменить Weibo и $B B S$. Тем не менее результаты опроса показали, что только 75,5\% опрошенных студентов знают, что в университетах и институтах начало функционировать интерактивное сообщество Yiban, но редко его используют, в т.ч. 54,8\% опрошенных никогда не пользовались Yiban. Опрос показал, что, по мнению студентов, обучающие и образовательные функции Yiban решительно не соответствуют требованиям и не могут заменить социальные и развлекательные функции, предоставляемые Weibo и WeChat на современном этапе.

\section{Анализ политических взглядов студентов шанхайских университетов}

На основе общей картины политических взглядов студентов в этом разделе сначала проводится факторный анализ, чтобы выбрать индикаторы измерения различных политических тенденций. Затем производится анализ отличий и взаимосвязь различных аспектов политической позиции студентов и, наконец, выявление корреляционной связи между степенью контактов в Интернете и политической позицией студентов. Анкета делит политические взгляды студентов по таким 7 позициям, как национализм, либерализм, рыночная экономика, политическая демократия, честность и справедливость, участие в политической жизни и политическое образование. Чтобы обеспечить единообразие измерений в каждом разделе и между разделами, в процессе анализа названия разделов в зависимости от их назначения корректируются, применяется метод анализа главных компонент в соответствии с величиной нагрузки по размеру объединений. При анализе политической позиции студентов семь влияющих факторов располагаются в зависимости от их вклада в нижеследующем порядке: участие в политической жизни, честность и справедливость, политическое образование, либерализм, рыночная экономика, национализм и политическая демократия (см. табл. 6).

Комбинируя взаимосвязь вышеуказанных аспектов политической позиции, мы можем в общих чертах судить о политических взглядах студентов университетов. Во-первых, чем более радикальна позиция студентов по отношению к национализму, тем более консервативна их позиция в вопросах либерализма, рыночной экономики, политической демократии. Во-вторых, чем более радикальна позиция студентов по отношению к либерализму, тем более радикальна их позиция по отношению к участию в политической жизни, рыночной экономике, политической демократии и, напротив, тем более консервативны будут их националистические взгляды. В-третьих, чем более радикальна позиция студентов университетов по отношению к рыночной экономике, тем более радикальна она и по отношению к участию в политической жизни, либерализму, политической демократии и, напротив более консервативна по отношению к национализму. В-четвертых, чем более радикальна позиция сту- 
дентов в отношении политической демократии, тем более радикальна она и по отношению к участию в политической жизни, либерализму и рыночной экономике и, напротив, более консервативна в отношении честности и справедливости, политического образования и национализма. В-пятых, чем более радикально настроены студенты по отношению к честности и справедливости, тем более консервативны они в отношении рыночной экономики, политической демократии и участия в политической жизни, и, напротив, еще более подчеркивается необходимость и эффективность идейно-политического воспитания. В-шестых, чем более радикальными являются студенты университетов в плане участия в политической жизни, тем более радикальны они и в плане либерализма, рыночной экономики и политической демократии и, напротив, тем более консервативны по отношению к честности и справедливости, при этом больше внимания уделяется необходимости и эффективности идейно-политического воспитания.

В целом, позиция по отношению к участию в политике студентов, изучающих гуманитарные науки, по сравнению со студентами, изучающими точные и естественные науки, более радикальна; студенты университетов из сельской местности более радикальны в вопросе честности и справедливости; политические взгляды студентов из военных семей в целом более консервативны, а студенты, чей семейный годовой доход занимает крайне противоположные позиции, более радикальны по отношению к участию в политической жизни.

\section{Связь между степенью интернет-общения и политической позицией}

Как упоминалось ранее, Интернет является основным источником информации для студентов. Так существует ли определенная взаимосвязь между степенью их интернет-общения и политической позицией? С помощью анализа независимой выборки средней величины из статической суммы средних величин выяснилось следующее. Во-первых, ответы на вопросы: «Используете ли вы сеть в основном для понимания социальной динамики?» и «Используете ли вы сеть в основном для понимания текущей политики?» имеют серьезное влияние на политическую позицию по 5 аспектам политических взглядов: это участие в политической жизни, либерализм, рыночная экономика, политическая демократия. Студенты, которые «используют сеть в основном для понимания социальной динамики» и «используют сеть в основном для понимания текущей политики», более радикальны в отношении участия в политической жизни, либерализма, рыночной экономики, политической демократии и, наоборот, не соглашаются с необходимостью и эффективностью идейно-политического воспитания.

Во-вторых, на такие аспекты политических взглядов, как политическое воспитание и политическая демократия, оказывает серьезное влияние ответ на вопрос: «Будете ли вы доверять Интернету, если в отношении одного и того же публичного мероприятия СМИ публикуют противоречивые сведения?» Студенты, которые «доверяют», являются более радикальными в аспекте политической демократии и, напротив, не согласны с необходимостью и эффективностью идейно-политического воспитания. В-третьих, на такие аспекты политических взглядов, как участие в политической жизни, политическое образование, рыночная экономика, национализм и политическая демократия, оказывает серьезное влияние ответ на вопрос: «Если в обществе существует сравнительно большой спорный вопрос или трудное для понимания общественное мероприятие, склонны ли вы обратиться к Интернету для лучшего понимания вопросов?» Студенты, которые склонны обращаться к Интернету, оказываются более радикальными по отношению к участию в политической жизни, рыноч- 
ной экономике, политической демократии и, напротив, в политическом образовании и национализме демонстрируют консерватизм.

\section{Выводы.}

Во-первых, некоторым студентам университетов не хватает базовой политической грамотности, особенно студентам естественнонаучных и технических дисциплин. В настоящее время студенты являются важным источником пополнения личного состава партийных кадров, однако данные опроса показывают, что члены партии, обучающиеся в вузах, не демонстрируют большей степени политической зрелости, чем другие группы студентов.

Во-вторых, студенты в целом выражают единство взглядов в отношении политической демократии, либерализма, рыночной экономики, участия в политической жизни. Однако студенты, которые более симпатизируют либерализму, политической демократии, рыночной экономике, имеют более слабые чувства справедливости, национальной идентичности, необходимости политического воспитания.

В-третьих, Интернет оказывает существенное влияние на политические взгляды студентов. Чем чаще студенты обращаются к Интернету для получения информации, тем более радикальна их позиция по отношению к политической демократии, либерализму, рыночной экономике и участию в политической жизни и тем менее они одобряют курс идейно-политического воспитания и его эффективность. Однако и те студенты, которые согласны с необходимостью и эффективностью идейно-политического воспитания, также уделяют большое внимание политике.

Понимание политического признания, политической позиции и возможных моделей поведения студентов может дать идеи для современной работы по идейно-политическому воспитанию в высших учебных заведениях. Опрос показал, что политические взгляды студентов шанхайских университетов, как правило, умеренные, без ультракрайних подходов. Студенты университетов обладают сравнительно сильным патриотическим духом, однако их любовь к родине не отличается фанатизмом и иррациональностью. Они имеют высокую степень признания ценности свобод, демократии, участия, а также сильное чувство честности и справедливости. Они отвергают западный либерально-демократический режим как чуждую губительную среду, в то же время преисполнены уверенности в правильности демократической политики и в политическом пути развития современного социалистического строя с китайской спецификой. Это показывает, что общая политическая позиция студентов университетов, выросших в эпоху Интернета, умеренная и рациональная.

Кроме того, исследование показало, что Интернет оказывает значительное влияние на политическую позицию студентов университетов. Попытки создать современную социальную сеть на территории университетских городков, которая обеспечила бы эффективную помощь Интернета студентам, по-прежнему необходимы.

\section{Список литературы}

Ле Юань, Ян Босю. 2009. Идеологическая позиция и политические фракции в национальном Интернете. - Журнал «XXI век». № 4.

Чжан Миншу. 2013. Какая демократия нужна китайцам. Пекин: Академическое издательство по общественным наукам.

Ма Дэюн, Чжан Шуся. 2014. «Левые» и «правые» пользователи китайского Интернета. - Журнал «ХХІ век». № 4. 
Nathan A.J., Tianjian Shi. 1996. Left and Right with Chinese Characteristics: Issues and Alignments in Deng Xiaoping's China. - World Politics. Vol. 4. No. 48. P. 522-550.

Li Xu, Ph.D., Cand.Sci. (Pol.Sci.), Senior Lecturer at the Institute of Marxism, East China University of Political Science and Law(1575 Wanghangdu St, Shanghai, China, 200042; lixu1210@mail.ru)

\section{STUDY OF THE POLITICAL POSITION OF UNIVERSITY STUDENTS IN THE INTERNET AGE (based on questionnaires from five universities in Shanghai)}

Abstract. Based on a survey of the political views of students at five Shanghai universities, this article summarizes the following: the political views of university students who grew up in the Internet age are generally moderate and rational, without a distinctly extreme position; they have a strong sense of patriotism, but without fanaticism or irrationality; they all have a fairly high degree of commitment to freedom, democracy, participation, and also have a fairly strong sense of justice; they reject the western liberal-democratic regime as an alien, destructive environment, at the same time they are full of confidence in the democratic policy and the political path of development of the modern socialist system with Chinese characteristics.

Keywords: Internet, student, political views 